\title{
DESENVOLVIMENTO DO PROFISSIONAL DA INFORMAÇÃO PARA ATUAR EM SAÚDE: IDENTIFICAÇÃO DE COMPETÊNCIAS
}

Vera S. M. Beraquet

Renata Ciol

Simone L. G. de Oliveira

Natalia M. Chiavaro

Márcio Alexandre N. Chagas

\section{Resumo}

Este trabalho apresenta resultados de pesquisa financiada pelo $\mathrm{CNPq}$ e trata da identificação das competências necessárias ao profissional da Informação que deseja atuar na área da saúde levando-se em conta as atuais demandas informacionais e educacionais. Foi utilizado o método qualitativo, com abordagem exploratória, aplicado através de entrevistas semiestruturadas. A amostra intencional foi composta por 36 sujeitos das áreas de Saúde, Educação e Ciência da Informação da cidade de Campinas. Este trabalho apontou, dentre outros resultados, as disciplinas básicas para um programa dessa natureza, a época de sua realização, bem como as competências essenciais para atuar em saúde.

Palavras-Chave

Informação em saúde; Formação profissional; Competência profissional; Interdisciplinaridade.

\section{THE SHAPING OF INFORMATION PROFESSIONALS TO ACT IN HEALTH AREA: COMPETENCIES' IDENTIFICATION}

\begin{abstract}
This work presents the findings of a research supported by $\mathrm{CNPq}$, which has had as main objective identify the required abilities of an information professional who intends to work in the health area, according to new informational and educational demands. The qualitative method was used, with exploratory field-work involving an intentional sample of 36 subjects from the city of Campinas (SP, Brazil), from the Health, Education and Information Science areas, who were interviewed. The search pointed out, among other results, the basic disciplines that should be contained in a program of such a nature, its place in the curriculum, as well as the essential abilities needed by the health information librarian.
\end{abstract}

\section{Keywords}

Health information; Professional formation; Professional competencies; Interdisciplinarity. 


\section{INTRODUÇÃO}

Questionamentos sobre delimitação de fronteiras entre as diversas áreas de conhecimento sempre estiveram presentes entre educadores e pesquisadores das áreas de humanas e sociais e se refletem na busca da disciplinaridade e da ampliação do diálogo entre as áreas para a construção do saber interdisciplinar, ou seja, saber comum a diferentes disciplinas.

O modelo linear de construção da ciência proposto por Vannevar Bush em 1945, no documento Science, the endless frontier, que basicamente valorizou o papel fundamental da ciência e tecnologia na sociedade e é ainda amplamente utilizado, começa a ter o "mito do benefício infinito" questionado.

Desde os anos 60, os norte-americanos têm trabalhado mais horas, descansado cada vez menos, viram aumentar a distância entre ricos e pobres; observaram a taxa de desemprego crescer e todos os indicadores de bem-estar social diminuírem (SAREWITZ, 1996).

Particularmente, em se tratando da saúde, observou-se uma grande contradição. A promessa implícita no relatório de Bush de que mais pesquisa biomédica traria mais saúde e melhor atendimento médico a toda população não se confirmou. A taxa de investimento em pesquisa em saúde cresceu ao longo dos anos, porém os custos médicos aumentaram (ironicamente em razão das novas tecnologias e drogas descobertas) e a assistência médica naquele país tornouse basicamente privilégio daqueles que podem pagar por ela.

Estados Unidos e Brasil, embora com sistemas de saúde diferentes, têm realizado grandes investimentos em pesquisas na área, como o mapeamento genético, para usar apenas um exemplo, cujos resultados alcançados até o momento demonstraram pouca eficácia na saúde pública e na melhoria da qualidade de vida da população.

No momento em que se percebe deterioração cada vez maior dessa qualidade de vida em razão de fatores como estresse, desemprego, fome, violência, falta de moradia e doença, é preciso refletir sobre os meios que a sociedade têm - com o suporte da comunidade científica 
- para reverter essa realidade em busca de um mundo menos desigual, mais saudável e com maior eqüidade de acesso aos bens públicos.

A biblioteconomia tradicional da posse, do armazenamento e da preservação da informação também tem sido transformada pelos paradigmas global e informacional das redes e da internet. O papel e a atuação do bibliotecário nesse início de século, conseqüentemente, vem se modificando e exigindo, principalmente das instituições responsáveis por sua formação, novas visões e um completo rearranjo de seu saber-fazer.

Segundo Terra (2001), as habilidades do trabalhador atual, conhecido como operário do conhecimento, são exatamente as mesmas exigidas do profissional da informação:

- acesso efetivo à informação;

- avaliação e validação da informação;

- $\quad$ organização e proteção da informação;

- atuação em rede: colaboração, publicação e disseminação da informação.

A formação bibliotecária tradicionalmente segue um modelo de planejamento sistêmico com atividades ligadas ao ciclo informacional (geração, organização, disseminação e uso da informação). Entretanto, como mediador da informação, o bibliotecário precisa garantir a efetiva comunicação entre os atores do fluxo informacional, o que sinaliza para uma intensificação de um trabalho mais abstrato que operacional (MIRANDA, 2004). Pode-se apontar também para a atuação fora dos limites das bibliotecas, sem que haja abandono do núcleo da profissão.

\section{REVISÃO DE LITERATURA}

A Ciência da Informação encontra-se em estágio evolutivo cuja discussão central é a delimitação de seu objeto de estudo e de suas teorias, além das metodologias que conformam a área (MARTELETO, LARA, 2004).

Embutida nessas discussões destaca-se a questão da interdisciplinaridade que a Ciência da Informação permite, ao possibilitar a convivência e a justaposição de diversas disciplinas ao seu arcabouço teórico, sem confundir o conceito de interdisciplinaridade com a mera adoção 
de conceitos e aplicações de outras áreas sem profunda reflexão sobre o objeto de conhecimento da Ciência da Informação.

Instituições como a ANCIB e a ABECIN vêm aprofundando o estudo acerca do ensino e da pesquisa na área de informação, por meio de discussões concernentes às diretrizes curriculares e o papel dos cursos de graduação e de pós na formação bibliotecária. O objetivo é que esses profissionais sejam capazes não apenas de atuar no crescente mercado informacional, mas também aptos a refletir sobre a área, de modo a consolidar e fortalecê-la.

A questão da interdisciplinaridade com o campo da saúde, no Brasil, deve-se em grande parte à reforma sanitária que criou, em 1988, o Sistema Único de Saúde - SUS. A partir desse momento, a saúde pública no país começou a consolidar uma posição de destaque nas políticas públicas, alterando a prática dos profissionais de saúde, dos gestores e, como não poderia deixar de ocorrer, a dos bibliotecários participantes desse sistema.

Entretanto, essa mudança ainda não chegou à universidade, pois o pequeno (porém crescente) número de pesquisas sobre a inclusão do bibliotecário nos serviços de saúde reforça a necessidade de se aprofundarem estudos sobre o tema no cenário nacional.

Ao estudar as possibilidades de atuação do bibliotecário em equipes multidisciplinares de saúde, pretende-se contribuir para uma reflexão teórica sobre uma inserção profissional que já existe na prática, porém ainda se restringme às bibliotecas médicas, algumas iniciativas internacionais - biblioteconomia clínica - e nacionais, como as bibliotecas virtuais em saúde.

São exemplos atuais do trabalho com a informação em saúde, mas que não conformam tema de pesquisa corrente em Ciência da Informação. De acordo com Horjland (2005), precisamos de pessoas e de argumentos que se mostrem visíveis e possam fortalecer um trabalho multidisciplinar em direção a uma melhor fundamentação teórica em Ciência da Informação.

Nessa linha de raciocínio, talvez seja o momento de se fazer um processo reflexivo sobre a inclusão da Ciência da Informação em áreas como a Saúde, com possível análise e proposta de mudança dos currículos dos cursos de biblioteconomia, voltados para a atuação nessa área. 
O bibliotecário clínico, por exemplo, define-se como membro da equipe de saúde e um dos responsáveis pela decisão sobre quais procedimentos adotar.

Esse profissional, que atua fora das bibliotecas e centros de informação, diferencia-se por necessitar de capacitação específica para agir em saúde. Não se pede que ele tenha necessariamente "formação básica médica", mas é essencial que seja a pessoa certa a fornecer respostas adequadas a questões que surgem durante o atendimento médico, por meio de provisão de literatura relevante e de qualidade, além de imediata. A mudança que se vislumbra é sair dos serviços de bibliotecas e passar para o serviço de apoio ao processo decisório, permanecendo, porém, a essência do trabalho bibliotecário.

Surge então a questão: qual é a essência da Ciência da Informação ao considerarmos que ciência insere-se em cada contexto sócio-cultural e não se constitui em algo isolado?

Após a Segunda Guerra Mundial, aconteceu a relativização da ciência como depositária da verdade e do bem; a partir daí a visão ideal de ciência pura vem sendo substituída pelo diálogo com outros tipos de conhecimento.

Nessas abordagens incluem-se a multidisciplinaridade, onde as disciplinas se juntam mas não se misturam; a interdisciplinaridade, que é a formação de espaço comum para solucionar questões teóricas; e a transdisciplinaridade, que são os paradoxos que passam a conviver em um novo espaço ao construir pontes entre as disciplinas.

A discussão que se tem pela frente é tentar identificar se Ciência da Informação e Saúde são inter ou transdisciplinares, pensando num processo crescente, em que o trabalho conjunto atinja, num grau máximo, a transdisciplinaridade.

No momento, a área parece estar tendendo para a multisdisciplinaridade, quando profissionais de diferentes especializações compartilham o mesmo espaço de trabalho, mas é pouco expressiva a efetiva interação de conhecimentos. 
A síntese do Congresso de Locarno, ocorrida na Suíça em 1997, apontou a busca da universidade pela evolução transdisciplinar, ao considerar os seguintes "aprenderes" do século XXI:

a) aprender a conhecer

b) aprender a fazer (educação interior, formação, profissão)

c) aprender a viver em conjunto (respeito a si e aos outros)

d) aprender a ser (desafio da auto-descoberta em lidar com o saber e o não saber)

Como alternativa, volta-se a discutir a educação e formação integral do ser humano. Uma das possíveis formas de se alcançar esse desenvolvimento com foco na transdisciplinaridade é fomentar o diálogo, o debate e a discussão entre todos os envolvidos, buscando um passo adiante na cristalização desse processo com a inclusão de temas e objetos do campo da saúde nos currículos de Ciência da Informação.

Iniciativas nesse sentido já existem, como é o caso da Universidade de Amsterdam, na Holanda, que criou um programa de quatro anos cujo currículo de Ciência da Informação é voltado para o trabalho do profissional da informação na área da saúde, de forma a incluir a multidisciplinaridade e a comunicação da informação entre os profissionais de saúde (JASPERS et al, 2003). Com foco interdisciplinar, esse programa tem como objetivo capacitar o bibliotecário nas questões de gerenciamento, tratamento e prevenção de doenças, noções sobre medicina molecular e sobre gestão do cuidado da saúde, implicando na sua inserção na equipe de saúde. Os bibliotecários recebem, em linhas gerais, conhecimentos fundamentais sobre medicina humana, problemas da prática na área e cuidados à saúde.

Essas e outras experiências de sucesso em países como Inglaterra, Estados Unidos e Alemanha levantam possibilidades de discussão sobre a viabilidade desses programas no Brasil; esse é um dos eixos motivadores da pesquisa aqui relatada.

\section{A PESQUISA}


O projeto de pesquisa "Gestão da Informação em Saúde: capacitação e inserção do profissional bibliotecário", financiado pelo CNPq e desenvolvido pelo Grupo de Pesquisa em Informação em Saúde da PUC-Campinas, tem como objetivo identificar possíveis meios de inserção do bibliotecário no campo da saúde, para trabalhar em equipes multidisciplinares.

No Brasil, como resultado da reforma sanitária, que culminou em 1988 com a criação do Sistema Único de Saúde (SUS), a saúde pública consolidou posição de destaque dentre as políticas públicas, alterando a prática dos profissionais de saúde, dos gestores e, como não poderia deixar de ocorrer, a dos bibliotecários que fazem parte desse sistema.

A preocupação da Pontifícia Universidade Católica de Campinas com a qualidade do ensino e sua política educacional voltada para fomentar e ampliar o que denomina "ensino com pesquisa", teve grande importância para a constituição desse grupo de pesquisa na Faculdade de Biblioteconomia, cujo objetivo é incluir todas as disciplinaridades (multi, pluri, inter e trans) nos campos da Ciência da Informação e da Saúde.

Pretende-se que os resultados dessa pesquisa possam colaborar com o arcabouço teórico da Ciência da Informação e o conseqüente aprimoramento dos currículos dos cursos de graduação e pós em Biblioteconomia, ao tentar identificar as competências necessárias aos bibliotecários para agir em saúde, e com isso delinear um perfil que corresponda às expectativas desses profissionais, de seus empregadores e da sociedade como um todo.

A pesquisa qualitativa foi baseada em entrevistas semi-estruturadas que envolveram docentes da área de Educação, docentes da área de Ciência da Informação e profissionais da saúde da cidade de Campinas (SP).

Tabela 1: Universo da pesquisa

\begin{tabular}{|c|c|c|c|c|c|c|c|c|c|}
\hline \multirow[b]{2}{*}{ ÁREA } & \multicolumn{4}{|c|}{ TITULAÇÃO } & \multicolumn{5}{|c|}{ "TEMPO DE ATUAÇÃO (EM ANOS) } \\
\hline & Graduação & Especialização & Mestrado & Doutorado & \begin{tabular}{|c|} 
Menos de \\
10
\end{tabular} & 10 a 15 & 15 a 20 & 20 a 25 & \begin{tabular}{|c|} 
Mais de \\
25
\end{tabular} \\
\hline Saúde (10) & 4 & 0 & 5 & 1 & 4 & 4 & 2 & 0 & 0 \\
\hline Educação (11) & 0 & 1 & 4 & 6 & & 3 & 2 & 1 & 5 \\
\hline \begin{tabular}{|l|} 
Ciência da \\
Informação (15)
\end{tabular} & 1 & 0 & 9 & 5 & 3 & 1 & 2 & 4 & 5 \\
\hline
\end{tabular}


O presente artigo analisa os resultados obtidos dos docentes de Ciência da Informação (15 entrevistados) e de Educação (11 profissionais), além dos profissionais da saúde (10) com relação às competências necessárias ao bibliotecário para trabalhar na área da saúde.

Quanto aos conhecimentos necessários ao bibliotecário para atuar em saúde, os docentes da Ciência da Informação apontaram:
a) terminologia da saúde;
b) noções básicas sobre a saúde e especialidades;
c) diversas finalidades de uso da informação em saúde;
d) políticas públicas de saúde;
e) fluência em um segundo idioma;
f) sistema de informação em saúde.

Em relação ao melhor momento de formação do bibliotecário para atuar em saúde, foram apontados:
a) graduação, no último ano;
b) especialização em nível de pós-graduação;
c) iniciação científica;
d) graduação, no terceiro ano;
e) mestrado.

As disciplinas consideradas fundamentais pelos docentes da Ciência da Informação se referem:
a) terminologia em saúde;
b) metodologia de pesquisa;
c) organização e disseminação da informação em saúde;
d) especialidades básicas em saúde;
e) introdução e história da saúde;
f) gestão da informação e do conhecimento em saúde;
g) políticas públicas da saúde;
h) administração hospitalar;
i) epistemologia, englobando todas as ciências. 
Para o desenvolvimento de currículo, devem ser observados os seguintes passos:

1) conhecer o público alvo;

2) discussão em grupos de pesquisa;

3) analisar programas de cursos da saúde;

4) especificação do perfil do profissional que se pretende formar;

5) identificar e descrever objetivos de programa;

6) realizar intercâmbio com profissionais;

7) promover experiências práticas;

8) divulgar o novo curso.

Em relação ao exercício da docência no programa, os docentes da Ciência da Informação apontaram:

a) ambos os profissionais;

b) atuação multidisciplinar.

Quanto à elaboração de novo currículo para o profissional da informação atuar em saúde, os 11 docentes da Educação contatados (PUC-Campinas) indicaram:

Condições de desenvolvimento:
a) conhecimento e atendimento às normativas do MEC;
b) formação de equipes para discussão;
c) currículo flexível;
d) autonomia universitária;
e) integração do ensino com a pesquisa.

Quanto aos passos a serem seguidos:
a) diagnosticar o contexto;
b) estudar propostas e cursos externos;
c) consultar legislação de educação;
d) consultar e envolver o corpo docente;
e) levantar objetivos e necessidades pedagógicas;
f) estabelecer e organizar disciplinas;
g) identificar infra-estrutura necessária;
h) elaborar projeto de curso generalista;
i) estabelecer cronograma de trabalho; 
j) reavaliar freqüentemente o processo.

Em relação às estratégias de desenvolvimento do programa devem ser considerados:
a) exercer a interdisciplinaridade;
b) consultar o estado da arte na área da saúde;
c) relacionar a teoria com a prática;
d) construir software específico.

O melhor momento de sistematização da formação profissional do bibliotecário para atuar em saúde:
a) pós-graduação;
b) cursos de extensão;
c) educação continuada;
d) graduação.

Referente às estratégias de docência em salas de aulas foram apontados:
a) integrar a teoria e a prática;
b) desenvolver trabalho de campo;
c) discutir teoria com profundidade;
d) relacionar a saúde com outras áreas;
e) levantar situações reais.

Em relação à prática das estratégias apontadas colocou-se:
a) exercício da pesquisa em grupo;
b) vivenciar experiências praticas;
c) trazer profissionais atuantes;
d) ruptura do censo comum;
e) disponibilizar laboratórios pedagógicos;
f) interdisciplinaridade;
g) adotar vídeos;
h) acesso à publicação e corpo docente.

No oferecimento de disciplinas os docentes da educação apontaram: 
a) ambos os profissionais, atuando em conjunto em grupos de pesquisas;

b) profissionais multidisciplinares;

c) docentes de ciências humanas;

d) docentes da ciência da informação.

O terceiro segmento do universo de pesquisa saiu do escopo acadêmico e incluiu 10 profissionais atuantes do sistema municipal de saúde da cidade de Campinas (Secretaria Municipal da Saúde e Hospital das Clínicas da Universidade Estadual de Campinas).

Quando questionados a respeito dos conhecimentos, atitudes e habilidades necessários ao bibliotecário, tendo em vista a sua contribuição para a saúde em equipes multidisciplinares, os profissionais da saúde consideram fundamentais:

Quanto aos conhecimentos:
a) políticas públicas (burocracia hospitalar);
b) saúde pública e SUS, assistência em saúde e epidemologia;
c) indicadores de saúde;
d) processo saúde-doença;
e) epistemologia e;
f) ciências sociais.

Quanto às atitudes:
a) atuação sem preconceitos;
b) bom senso e ética.

Quanto às habilidades:
a) comunicação verbal e não verbal eficazes;
b) trabalho em equipes multidisciplinares;
c) uso de tecnologias de informação, fontes bibliográficas e de informação na área da saúde;
d) domínio do idioma inglês para leitura e escrita.

As exigências requeridas ao bibliotecário na saúde se devem à expectativa de atuação desse profissional, conforme percebe-se na afirmação de Schacher:

[...] O bibliotecário clínico é membro de equipes de profissionais da saúde que se reúnem diariamente em vários centros médicos e hospitais; a presença do bibliotecário clínico nessas reuniões é devida 
à sua agilidade em responder questões feitas pelos clínicos no momento das reuniões. Quando a resposta imediata não é possível, o bibliotecário clínico anota a questão e posteriormente (poucas horas após) encaminha a resposta à equipe que o solicitou. Na ocorrência de questões complexas, o bibliotecário clínico dirige-se a biblioteca, lança mão dos recursos disponíveis (bases de dados, periódicos, etc.) e realiza pesquisas para a obtenção da resposta. (SCHACHER, 2001, p. 719).

\section{CONCLUSÕES E RECOMENDAÇÕES}

Os resultados obtidos reforçam a necessidade de se discutir a preparação do profissional da informação para atuar em equipes multidisciplinares juntos aos profissionais da saúde, o que envolve o domínio sobre as fontes de informação relevantes para a atuação e decisão dos responsáveis pela saúde da população.

Esse reconhecimento é um indicativo às Faculdades de Biblioteconomia de que o currículo tradicional pode ser revisto e enriquecido tendo em vista a formação de um profissional que consiga ter um novo olhar sobre si, sobre os outros, e sobre o que ele sabe e pode fazer considerando novas perspectivas de atuação profissional.

Ao considerarmos que a explosão informacional e o desenvolvimento de redes e de meios que facilitam seu fluxo eficiente têm aumentado o poder da informação na sociedade contemporânea, podemos ao mesmo tempo concluir que "não existe teste prévio para reconhecer a boa e a má informação, a verídica e a falsa" (MORIN, 1986), o que demanda cada vez mais especialistas em informação capazes de trazer e oferecer a informação relevante e destacar o que não é importante, ou pior ainda, o que não é verdade.

O bibliotecário, com toda bagagem teórica e prática recebida nos cursos de graduação e de pós, pode e deve contribuir para a melhoria da saúde no país - notadamente a saúde pública por ser capaz de levantar a informação mais adequada para que todos os que tomam decisão em saúde definam ações baseadas em conhecimento e que tenham respaldo técnico-científico.

A pós-graduação da área deve pesquisar também nas fronteiras de seu conhecimento; é necessário transformar em ação o discurso interdisciplinar da área, expandindo sua visão sobre a informação. 
Aos poucos, Ciência da Informação e Saúde caminham para a interdisciplinaridade desejada e poderão contribuir, ambas, não somente para a especificidade de suas áreas, como também para a melhoria da qualidade de vida da população.

Pelo que apontaram os entrevistados, parece consenso que o bibliotecário precisa conhecer os aspectos básicos que envolvem a saúde pública no país, principalmente o que se relaciona com fontes de informação em saúde, gestão de serviços de saúde, sistemas de informação voltados à saúde, fluxos de informação e conhecimentos nas várias instâncias do SUS, arquivos e documentação em saúde, dentre outros. Essa constatação aumenta ainda mais a responsabilidade do profissional da informação frente à sociedade, pois conhecer a política dos sistemas de saúde e do sistema de fomento à pesquisa pode significar o aumento gradual da inclusão das questões de saúde pública nas pesquisas financiadas pelo Governo.

O bibliotecário, desse modo, pode resgatar e ampliar seu papel social, antes restrito às bibliotecas públicas e escolares, para o escopo mais complexo da saúde, que exige saber trabalhar não apenas na biblioteca, mas ter competência e flexibilidade para realizar as atividades de bibliotecário dentro de ambientes diferenciados. Aliás, vale ressaltar que este papel social do profissional ganha força com a mudança do enfoque institucional (bibliotecas públicas e escolares) para o enfoque temático (saúde, agricultura, educação etc..).

Cabe às Faculdades de Biblioteconomia, preocupadas com o novo profissional da informação, estenderem e ampliarem as investigações sobre as competências essenciais ao bibliotecário. Porém, tão urgente quanto, é que os cursos e programas adotem medidas reais, mesmo que tímidas no princípio, que possam ir transformando o bibliotecário num ser interdisciplinar cada vez mais flexível e indispensável a qualquer área do conhecimento.

Flexibilidade e competências de comunicação, como apontado pelos entrevistados, podem efetivamente posicionar o bibliotecário na gestão dos serviços de informação em saúde, razão pela qual se faz necessário conhecer os aspectos políticos que envolvem a área, além de dominar a tarefa de elaborar e executar projetos. 
Pode ser observado que geralmente o profissional bibliotecário é flexível ao trabalhar com outros profissionais, mas tem se mostrado resistente a mudanças quando se trata em oferecer serviços e/ou disponibilizar informação aos usuários.

A Gestão do Conhecimento, em evidência na atualidade, significa o gerenciamento dos recursos humanos, físicos, financeiros e informacionais de uma organização, e apesar de não ter sido explicitamente citada na pesquisa, é consenso desse Grupo que os "novos" cursos de Ciência da Informação tenham componentes voltados à Saúde e incluam em seu escopo disciplinas gerenciais.

Conclui-se que a profissão do bibliotecário requer mudanças, não em sua base e conceitos, mas nos seus resultados e dinâmica de atuação; significa rever a ênfase de suas habilidades e de seus conhecimentos. As competências valorizadas na sociedade do conhecimento envolvem: experiência profissional, conhecimento de tecnologias de informação (web e ferramentas de interconectividade), domínio de outros idiomas, e competências de comunicação (oral, escrita e domínio da capacidade de compreensão e transmissão de idéias) além das competências básicas ligadas às respectivas temáticas dos campos de atuação.

Competência, nesse sentido, relaciona-se com aptidão, qualidade legitimada para executar determinados atos, capacidade objetiva de alguém para agir em determinada área do conhecimento (BUFREM; PEREIRA, 2004).

Fica claro que falta também às universidades melhor retratarem em seus cursos e programas as necessidades do mundo do trabalho e das instituições para que o bibliotecário não saia da Faculdade sem saber "ler os ambientes" e, talvez por não conseguir se posicionar, pode acabar restrito a tarefas apenas burocráticas, sem poder avançar nos serviços que oferece, sem fazer avançar a área, sem poder avançar em sua carreira e, o que é ainda mais complicado, eventualmente ser substituído por outros profissionais justamente por não ser competente para ocupar os espaços que lhe são abertos.

A discussão sobre formação e desenvolvimento profissional é tema recorrente em todas as áreas; ficam aqui subsídios para essa discussão com a vertente da interface temática entre as áreas Ciência da Informação e Saúde. 


\section{REFERÊNCIAS}

BUFREM, L. S.; PEREIRA, E. C. Os profissionais da informação e a gestão de competências. Perspectiva em Ciência da Informação, Belo Horizonte, v. 9, n. 1, p. 170181, jul./dez. 2004.

HJORLAND, B. Library and information science and the philosophy of science. Journal of Documentation, v. 61, n. 1, p. 5-10, 2005.

JASPERS, M. W.; FOCKENS, P.; RAVESLOOT, J. H.; LIMBURG M.; ABU- HANNA, A. Fifteen years medical information sciences: the Amsterdam curriculum. Internacional Journal of Medical Informatics, v. 73, n. 6, p. 465-477, June 2004.

MARTELETO, R. M.; LARA, M. L. G. Sobre o workshop de Ciência da Informação: políticas e estratégias de pesquisa e ensino na pós-graduação. In: ASSOCIAÇÃO NACIONAL DE PESQUISA E PÓS-GRADUAÇÃO EM CIÊNCIA DA INFORMAÇÃO ANCIB, 2004, Niterói. Workshop de Ciência da Informação: políticas e estratégias de pesquisa e ensino na pós-graduação. ANCIB/UFF, 2004.

MIRANDA, S. V. Identificando competências informacionais. Ciência da Informação, Brasília, v. 33, n. 2, p. 112-122, maio/ago. 2004.

MORIN, E. Para sair do século XX. Rio de Janeiro: Nova Fronteira, 1986.

SAREWITZ, D. Frontiers of illusion: science, technology and the politics of progress. Philadelphia: Temple, 1996.

SCHACHER, L. F. Clinical librarianship: its value in medical care. Annals of Internal Medicine, v. 134, n. 8, p. 717-720, 2001.

TERRA, J. C. C. Gestão do conhecimento: o grande desafio empresarial. 2. ed. São Paulo: Negócio Editora, 2001. 


\section{Vera S. M. Beraquet}

PhD em Ciência da Informação, Docente-Pesquisadora PUC-Campinas, grberaquet@puc-campinas.edu.br

\section{Renata Ciol}

Mestre em Ciência da Informação, rciol@uol.com.br

\section{Simone L. G. de Oliveira}

Mestre em Ciência da Informação, Bibliotecária UNICAMP, simone_lgo@yahoo.com.br

\section{Natalia M. Chiavaro}

Bolsista de Iniciação Científica PUC-Campinas, natchiavaro@yahoo.com.br

\section{Márcio Alexandre N. Chagas}

Bolsista de Iniciação Científica PUC-Campinas, cobyle@uol.com.br

Artigo aceito para publicação em janeiro de 2006. 